\title{
SYNTHESIS, CRYSTAL STRUCTURE, AND THERMAL DECOMPOSITION KINETICS OF HOLMIUM WITH BENZOATE AND 2, 2'-BIPYRIDINE COMPLEX
}

\author{
SUN JING SUN ${ }^{a, b}$, NING. REN ${ }^{c^{*}}$, SHU MEI HE ${ }^{a}$, JIAN JUN ZHANG ${ }^{a}$ \\ aInstrumental Analysis Center, Hebei Normal University, Shijiazhuang 050016 P. R. China: \\ ${ }^{b}$ No.1 High School of Dezhou, Dezhou 253000, P. R. China; \\ ${ }^{c}$ Department of Chemistry, Handan Key Laboratory of organic small molecular materials, Handan College, Handan 056005 P. R. China
}

\begin{abstract}
The complex $\left[\mathrm{Ho}(\mathrm{BA})_{3} \text { bipy }\right]_{2}$ (BA=benzoate; bipy=2,2'-bipyridine) was synthesized and characterized by elemental analysis, infrared spectra, ultraviolet spectra, single-crystal X-ray diffraction, thermogravimetry and differential thermogravimetry (TG-DTG) techniques. The crystal is monoclinic with space group $P 2_{1} / n$. The unit cell parameters are: $a=14.1114(8) \AA, b=15.3743(9) \AA, c=25.8887(14) \AA, \beta=103.555(2)^{\circ}$. Two Ho ${ }^{3+}$ ions are connected by four carboxylic groups through a bridging bidentate mode. The thermal decomposition behavior of the title complex under nitrogenous atmosphere was studied using the TG-DTG, and IR techniques. The non-isothermal kinetics was investigated by using the Popescu method and the integral iso-conversional non-linear method (NL-INT). The mechanism function of the first decomposition step was determined. The thermodynamic parameters $\left(\Delta G^{\neq}, \Delta H^{\ddagger}\right.$ and $\left.\Delta S^{\ddagger}\right)$ were also calculated, and kinetic parameters (activation energy $E$ and the pre-exponential factor $A$ ) were also obtained.
\end{abstract}

Keywords: Ho(III)complex, Crystal structure, Thermal decomposition mechanism, Non-isothermal kinetics

\section{INTRODUCTION}

In recent years, the lanthanide carboxylic acid complexes have been attracting more and more attention due to their fascinating architectures and potential applications as luminescence, magnetism, catalysis, and gas separation. ${ }^{1-5}$ Aromatic carboxylic acids and their derivatives have the multifunctional coordination sites with chelating and briding ability. 1,10-phenanthroline(1,10-phen) and 2'2-bipyridine(2'2-bipy) are good nitrogen-containg ligands for lanthanide ions, which can enhance the stability of polymers and luminescent properties of resulting complexes. A survey of literature shows that crystal structures and luminescent properties on ternary lanthanide complexes $(\mathrm{Ln}=\mathrm{Sm}, \mathrm{Eu}, \mathrm{Tb}, \mathrm{Dy}, \mathrm{Nd}, \mathrm{Gd}, \mathrm{Er})$ containing benzoic and its derivatives and 1,10-phen or 2'2-bipy have been investigated extensively. ${ }^{6-17}$ However thermal behaviour and non-isothermal kinetics of these complexes are rare in literatures. In material science, the investigation of thermal analysis for lanthanide aromatic carboxylic acids complexes is an important field. The study can get the relationship between the structures and stability, which can promote the coordination development structure.

In our previous works, a series of lanthanide carboxylate complexes were synthesized and characterized. ${ }^{15-19}$ Herein, the synthesis, crystal structure, thermal stability of the Ho(III) complex based on benzoic and 2'2-bipy were reported. And The kinetic parameters such as activation energy $E$ and the preexponential factor $A$ have been calculated using both Popescu method ${ }^{20}$ and the integral iso-conversional non-linear (NL-INT) method. ${ }^{21}$ The thermodynamic parameters $\Delta G^{\ddagger}, \Delta H^{\ddagger}$ and $\Delta S^{\ddagger}$ of activation on the peak temperature were also calculated.

\section{EXPERIMENTAL}

Materials and apparatus

All the reagents were used from commercial sources without further purification. $\mathrm{HoCl}_{3} \cdot 6 \mathrm{H}_{2} \mathrm{O}$ was prepared from $\mathrm{Ho}_{2} \mathrm{O}_{3}$ by treatment with concentrated hydrochloric acid.

Analyses of $\mathrm{C}, \mathrm{H}$, and $\mathrm{N}$ were performed on a Vario-EL III element analyzer, while the metal content was assayed using an EDTA titration method. The infrared spectra were recorded at room temperature in the range of $4000-400 \mathrm{~cm}^{-1}$ using a Perkin-Elmer FTIR-1730 spectrometer with $\mathrm{KBr}$ disk technique. The ultraviolet spectra were recorded on a Shimadzu 2501 spectrophotometer in DMSO (DMSO= dimethylsulfoxide). TG and DTG experiments for the title complex were performed using a Perkin-Elmer TGA7 thermogravimetric analyzer with the heating rate of $(3,5,10$, and 15$) \mathrm{K} \cdot \mathrm{min}^{-1}$ from ambient to $1173 \mathrm{~K}$ under nitrogenous atmosphere at a flow rate of 35 $\mathrm{cm}^{3} \mathrm{~min}^{-1}$.

The single crystal X-ray diffraction data were obtained by a $\mathrm{FC10} /$ Saturn724+ diffractometer at 293 K. Semi-empirical absorption corrections were applied using SADABS program. The structure was solved by direct methods using SHELXS-97 program and refined by Full-matrix least-squares on $F^{2}$ using SHELXL-97 program. A semiempirical absorption correction with SADABS was applied.

Synthesis

The molar ratio of $\mathrm{HoCl}_{3} \cdot 6 \mathrm{H}_{2} \mathrm{O} / \mathrm{HBA} /$ bipy was $1: 3: 1 . \mathrm{HoCl}_{3} \cdot 6 \mathrm{H}_{2} \mathrm{O}$ was dissolved in distilled water, and benzoic acid and $2,2^{\prime}$-bipyridine were dissolved in ethanol solution. The $\mathrm{pH}$ of the mixed ligands solution was controlled in a range of 6-7 with $1 \mathrm{~mol} \cdot \mathrm{L}^{-1} \mathrm{NaOH}$ solution. The complex was prepared by adding slowly the solution of the ligand to the solution of $\mathrm{HoCl}_{3} \cdot 6 \mathrm{H}_{2} \mathrm{O}$, with continuous stirring. The precipitates were washed with distilled water and ethanol solution, and dried in a desiccator. The single crystals were obtained by slow evaporation of the mother solution at room temperature after about two weeks. For $\mathrm{C}_{62} \mathrm{H}_{46} \mathrm{Ho}_{2} \mathrm{~N}_{4} \mathrm{O}_{12}$ anal. calcd,\%: C 54.40, H 3.39, N 4.09; Ho 24.11;found, \%: C 53.93, H 3.45, N 3.93. Ho 24.50

\section{RESULTS AND DISCUSSION}

\section{IR spectra}

The IR spectra of the free ligand HBA shows a strong absorption band at $1688 \mathrm{~cm}^{-1}$, which are assigned to the stretch vibration of the carboxylate group. The antisymmetric and symmetric absorption peaks about at 1640 $\mathrm{cm}^{-1}$ and $1416 \mathrm{~cm}^{-1}$ appear in the spectra of the complex, indicating that only the oxygen atoms of ligand were involved in coordination to $\mathrm{Ho}^{3+}$ ion..$^{15}$ In addition, the appearance of the band of $v(\mathrm{Ho}-\mathrm{O})$ at $428 \mathrm{~cm}^{-1}$ also indicates the conclusions above. The characteristic absorption bands of the free bipy ligand due to $v(\mathrm{CN})$ and $\delta(\mathrm{CH})$ appear at 1578,992 and $757 \mathrm{~cm}^{-1}$, respectively, which shift to long wave numbers $\left(1599,1013\right.$ and $\left.774 \mathrm{~cm}^{-1}\right)$ after the formation of the title complex. The results clearly show that the nitrogen atoms of bipy ligand participate in the coordination to $\mathrm{Ho}^{3+}$ ion. ${ }^{16}$

UV spectra

The UV spectra of the title complex and two ligands were depicted with DMSO as a reference at room temperature. The maximum absorption peak of HBA ligand at $260 \mathrm{~nm}$ shifts to $280 \mathrm{~nm}$ after coordination. It may be caused by the $\pi$-conjugated system due to metal coordination. ${ }^{22}$ In addition, the maximum absorption peak of the title complex at $280 \mathrm{~nm}$ is the same as that of free bipy ligand, but the molar extinction coefficient in the same wavelength is greatly enhanced, suggesting a bigger chelating ring has been formed.

Crystallographic study

Crystal data and structure refinement details for the title complex are summarized in Table 1, and selected bond lengths and angles are shown in Table 2.The structure of the complex $\left[\mathrm{Ho}(\mathrm{BA})_{3} \text { bipy }\right]_{2}$ is shown in Fig. 1. The molecular structure shows a center-related dinuclear unit. Each $\mathrm{Ho}^{3+}$ ion is eight-coordinated to two oxygen atoms from one bidentate chelating carboxyl group, four oxygen atoms from four bridging bidentate carboxyl groups, and two nitrogen atoms from one bipy molecule. It is similar to the reported isomorphous complexes [Ln(BA) bipy $]_{2}(\mathrm{Ln}=\mathrm{Nd}, \mathrm{Sm}, \mathrm{Eu}, \mathrm{Tb}, \mathrm{Dy}, \mathrm{Er}) .^{11-16} \mathrm{The}$ 
coordination geometry of the Ho(III)center is a trigonal dodecahedron (Fig. 2.) consisting of $\mathrm{O}(4), \mathrm{O}(6), \mathrm{O}(8), \mathrm{O}(10), \mathrm{O}(11), \mathrm{O}(12), \mathrm{N}(3)$ and $\mathrm{N}(4)$. It is the same to the coordination geometries of complexes $\left[\mathrm{Ln}(\mathrm{BA})_{3} \text { bipy }\right]_{2}(\mathrm{Ln}=\mathrm{Nd}$, $\mathrm{Sm}, \mathrm{Eu}, \mathrm{Tb}, \mathrm{Dy})$. But the coordination geometry of complex $\left[\operatorname{Er}(\mathrm{BA})_{3} \text { bipy }\right]_{2}$ is distorted square antiprisms due to the different symmetry.

The bond distances of Ho-O are in the range 2.267(2)-2.431(2) $\AA$, while those of Ho-N are in the range 2.542(3)-2.592(3) $\AA$. The average distance of Ho-O (the chelated carboxyl group, $2.397 \AA$ ) is longer than that of Ho-O (the bridging carboxyl group, $2.294 \AA$ ), maybe four-membered ring of chelating coordination has larger tension. Obviously, the distance between Ho and $\mathrm{O}$ atom is shorter than the length of Ho-N bond. So, the bond energy of Ho-O is stronger than Ho-N bond, which is in good agreement with the results of thermal decomposition process. Compared with the length of $\mathrm{Ln}-\mathrm{O}$ and $\mathrm{Ln}-\mathrm{N}$ in the complexes of $\left[\mathrm{Ln}(\mathrm{BA})_{3} \text { bipy }\right]_{2}(\mathrm{Ln}=\mathrm{Nd}, \mathrm{Sm}, \mathrm{Eu}, \mathrm{Tb}, \mathrm{Dy}, \mathrm{Ho}, \mathrm{Er})$, the Ln-O and Ln-N bond distances are shrinking From Nd to Er. This may be related to the shorter radius with the increment of atomic number caused by the result of lanthanide contraction. The average distances of Ho-O and Ho $-\mathrm{N}$ in this work are somewhat shorter than those of $\left[\mathrm{Ho}(\mathrm{BA}){ }_{3} \mathrm{phen}\right]_{2}^{18}$ due to stronger steric hindrance effect of phen than that of bipy.

Table 1. Crystal data and structure refinement of the title complex

\begin{tabular}{|c|c|}
\hline Parameter & Data \\
\hline Empirical formula & $\mathrm{C}_{62} \mathrm{H}_{46} \mathrm{Ho}_{2} \mathrm{~N}_{4} \mathrm{O}_{12}$ \\
\hline Formula weight & 1368.89 \\
\hline Temperature & $293 \mathrm{~K}$ \\
\hline Wavelength & $0.71073 \AA$ \\
\hline Crystal system, space group & Monoclinic, $\mathrm{P}_{1} / \mathrm{n}$ \\
\hline Unit cell dimensions & $\begin{array}{c}a=14.0771(16) \AA, \alpha=90^{\circ} \\
b=15.1839(16) \AA, \beta=103.555(2)^{\circ} \\
c=25.672(3) \AA, \gamma=90^{\circ}\end{array}$ \\
\hline Volume & $5334.5(10) \AA^{-3}$ \\
\hline Z, Calculated density & $4,1.704 \mathrm{Mg} / \mathrm{m} \AA^{-3}$ \\
\hline Absorption coefficient & $3.015 \mathrm{~mm}^{-1}$ \\
\hline $\mathrm{F}(000)$ & 2704 \\
\hline Crystal size & $0.30 \times 0.27 \times 0.23 \mathrm{~mm}$ \\
\hline Theta range for data collection & $(3.04 \text { to } 27.50)^{\circ}$ \\
\hline Limiting indices & $-18 \leq \mathrm{h} \leq 18,-16 \leq \mathrm{k} \leq 19,-32 \leq 1 \leq 33$ \\
\hline Reflections collected / unique & $43296 / 12169[\mathrm{R}(\mathrm{int})=0.0335]$ \\
\hline Completeness to $\theta=27.50$ & $99.3 \%$ \\
\hline Absorption correction & Empirical \\
\hline Max. and min. transmission & 0.5401 and 0.4649 \\
\hline Refinement method & Full-matrix least-squares on $\mathrm{F}^{2}$ \\
\hline Data / restraints / parameters & $12169 / 0 / 721$ \\
\hline Goodness-of-fit on $\mathrm{F}^{2}$ & 1.006 \\
\hline Final $R$ indices $[I>2 \sigma(I)]$ & $R_{1}=0.0298, \mathrm{w} R_{2}=0.0675$ \\
\hline$R$ indices (all data) & $R_{1}=0.0320, \mathrm{w} R_{2}=0.0691$ \\
\hline Largest diff. peak and hole & 0.953 and -0.645 e. $\AA^{-3}$ \\
\hline
\end{tabular}

Table 2. Selected bond lengths $(\AA)$ and angles $\left({ }^{\circ}\right)$ of the title complex

\begin{tabular}{|c|c|c|c|}
\hline $\mathrm{Ho}(1)-\mathrm{O}(4)$ & $2.267(2)$ & $\mathrm{Ho}(1)-\mathrm{N}(4)$ & $2.542(3)$ \\
\hline $\mathrm{Ho}(1)-\mathrm{O}(8)$ & $2.268(2)$ & $\mathrm{Ho}(1)-\mathrm{N}(3)$ & $2.592(3)$ \\
\hline $\mathrm{Ho}(1)-\mathrm{O}(10)$ & $2.308(2)$ & $\mathrm{O}(2)-\mathrm{C}(7)$ & $1.271(4)$ \\
\hline $\mathrm{Ho}(1)-\mathrm{O}(6)$ & $2.332(2)$ & $\mathrm{O}(1)-\mathrm{C}(7)$ & $1.254(4)$ \\
\hline $\mathrm{Ho}(1)-\mathrm{O}(11)$ & $2.362(2)$ & $\mathrm{Ho}(1)-\mathrm{O}(12)$ & $2.431(2)$ \\
\hline $\mathrm{O}(4)-\mathrm{Ho}(1)-\mathrm{N}(4)$ & $93.92(8)$ & $-\mathrm{O}(8)$ & $78.98(8)$ \\
\hline $\mathrm{O}(8)-\mathrm{Ho}(1)-\mathrm{N}(4)$ & $141.88(8)$ & $\mathrm{O}(4)-\mathrm{Ho}(1)-\mathrm{O}(6)$ & $78.09(8)$ \\
\hline $\mathrm{O}(10)-\mathrm{Ho}(1)-\mathrm{N}(4)$ & $75.68(8)$ & $\mathrm{O}(8)-\mathrm{Ho}(1)-\mathrm{O}(6)$ & $77.48(7)$ \\
\hline $\mathrm{O}(6)-\mathrm{Ho}(1)-\mathrm{N}(4)$ & $139.02(8)$ & $\mathrm{O}(10)-\mathrm{Ho}(1)-\mathrm{O}(6)$ & $138.14(7)$ \\
\hline $\mathrm{O}(11)-\mathrm{Ho}(1)-\mathrm{N}(4)$ & $85.06(8)$ & $\mathrm{O}(4)-\mathrm{Ho}(1)-\mathrm{O}(11)$ & $147.37(8)$ \\
\hline $\mathrm{O}(12)-\mathrm{Ho}(1)-\mathrm{N}(4)$ & $73.03(8)$ & $\mathrm{O}(8)-\mathrm{Ho}(1)-\mathrm{O}(11)$ & $92.51(8)$ \\
\hline $\mathrm{O}(10)-\mathrm{Ho}(1)-\mathrm{O}(12)$ & $79.33(8)$ & $\mathrm{O}(10)-$ & $133.75(8)$ \\
\hline $\mathrm{O}(6)-\mathrm{Ho}(1)-\mathrm{O}(12)$ & $125.82(7)$ & $\mathrm{O}(6)-\mathrm{Ho}(1)-\mathrm{O}(11)$ & $81.49(7)$ \\
\hline $\mathrm{O}(11)-\mathrm{Ho}(1)-\mathrm{O}(12)$ & $54.75(7)$ & $\mathrm{O}(4)-\mathrm{Ho}(1)-\mathrm{O}(12)$ & $154.87(8)$ \\
\hline
\end{tabular}

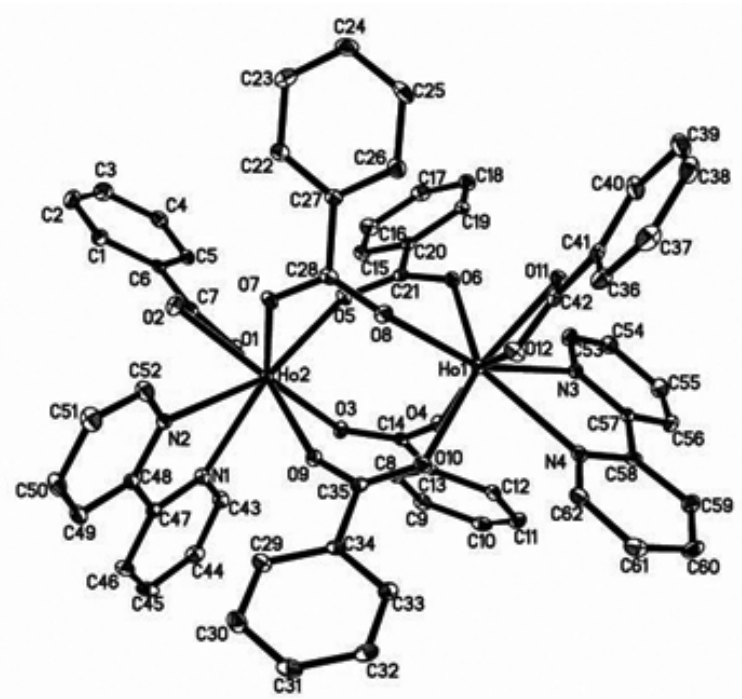

Figure 1. The molecular structure of the title complex

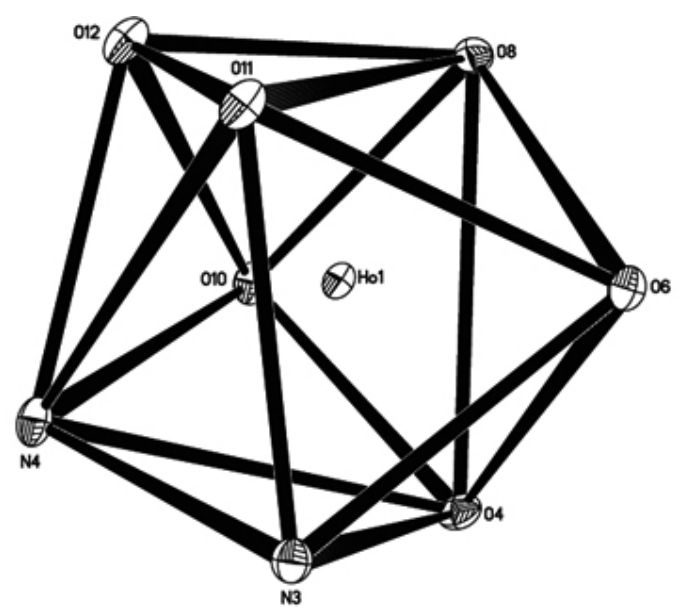

Figure 2. Coordination geometry of $\mathrm{Ho}^{3+}$ ion

Thermogravimetric analysis

Fig. 3 shows the thermoanalytical curves of the title complex at a heating 
rate of $15 \mathrm{~K} \cdot \mathrm{min}^{-1}$ under nitrogenous atmosphere. As shown from the DTG curve, in the temperature range 413.84-508.26 $\mathrm{K}$, the experimental loss weight $(\mathrm{w}=23.17 \%)$ was in good agreement with the loss of 2 bipy molecules. The second step took place between $508.26 \mathrm{~K}$ and $750.28 \mathrm{~K}$, and a part of $\mathrm{C}_{6} \mathrm{H}_{5} \mathrm{COO}^{-}$was lost. The third stage began at $750.28 \mathrm{~K}$ and ended at 1020.22 $\mathrm{K}$, which was the loss of residual $\mathrm{C}_{6} \mathrm{H}_{5} \mathrm{COO}^{-}$. Obviously, the loss of bipy ligand is earlier than that of benzoic acid ligand, which can be demonstrated by the bonds distance of the complex. The IR spectra of the intermediate residue at $573 \mathrm{~K}$ shows the disappearance of absorption band of $\mathrm{C}=\mathrm{N}$ at $1599 \mathrm{~cm}^{-1}$. The characteristic absorption band of the final residue is similar to the standard sample spectra of $\mathrm{Ho}_{2} \mathrm{O}_{3}$. Therefore, by $1020.22 \mathrm{~K}$, complex [Ho(BA), bipy] is completely degraded into $\mathrm{Ho}_{2} \mathrm{O}_{3}$ with the total weight loss of $72.53 \%$ (the theoretical mass loss is $72.40 \%$ ). Based on the analysis above, the thermal decomposition process of $\left[\mathrm{Ho}(\mathrm{BA})_{3} \text { bipy }\right]_{2}$ can be expressed in the following ways:

$\left[\mathrm{Ho}(\mathrm{BA})_{3} \mathrm{bipy}\right]_{2} \rightarrow\left[\mathrm{Ho}(\mathrm{BA})_{3}\right]_{2} \rightarrow\left[\mathrm{Ho}_{2}\left(\mathrm{C}_{6} \mathrm{H}_{5} \mathrm{COO}^{-}\right)_{6-\mathrm{x}}\right] \rightarrow \mathrm{Ho}_{2} \mathrm{O}_{3}$

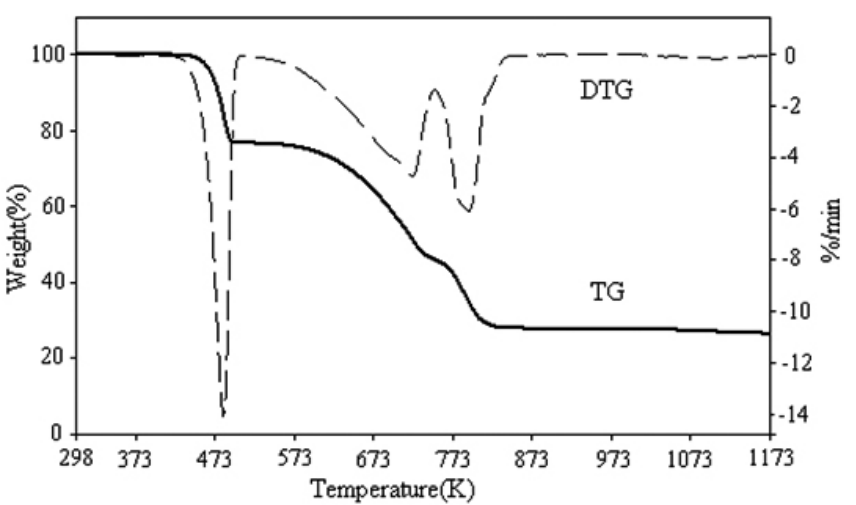
$\mathrm{K} \cdot \min ^{-1}$

Figure 3. TG-DTG curves of the title complex at a heating rate of 15

\section{Non-isothermal thermoanalysis kinetics}

The dependence of the activation energy $E$ on conversion $\alpha$ of the first decomposition stage by using integral isoconversional non-linear method is displayed in Fig. 4. As shown in Fig.4, the values of the activation energy $E$ remain almost constant with different conversion $\alpha$. It can be concluded that the first decomposition process is a single step reaction. ${ }^{23}$ So the probable mechanism function can be obtained by means of Popescu method.

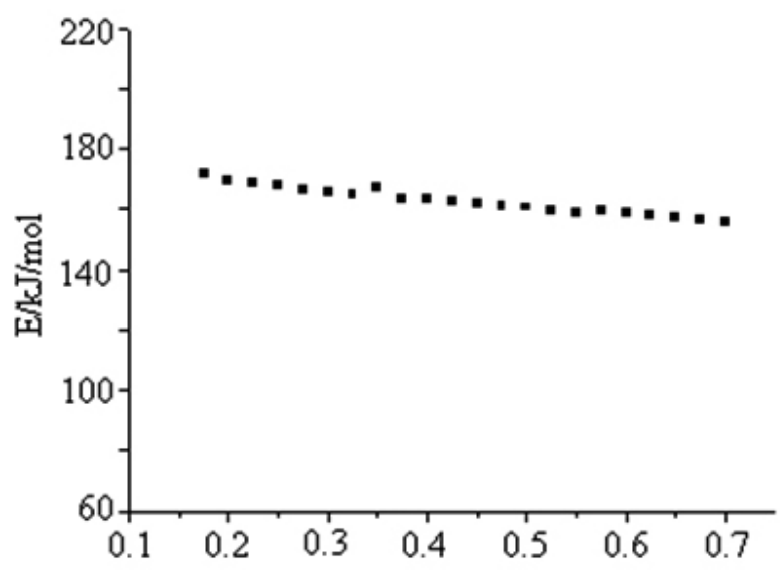

Figure 4. The relationship of $E$ and $\alpha$ of the first decomposition stage of the complex

Popescu Method

The determination of $f(\alpha)$ and $G(\alpha)$

The Popescu method was applied to study the kinetics of the thermal decomposition process of the title complex. The main equations are described as follows

$$
\begin{gathered}
G(\alpha)_{m n}=\int_{\alpha_{m}}^{\alpha_{n}} \frac{d \alpha}{f(\alpha)} \\
I(T)_{m n}=\int_{T_{m}}^{T_{n}} K(T) d T \\
G(\alpha)_{m n}=\frac{1}{\beta} I(T)_{m n}
\end{gathered}
$$

Where $\alpha_{m}, \alpha_{n}$ are two different degrees of conversion and $T_{m}, T_{n}$ are their corresponding temperatures. The method assumes that the kinetics of the reaction does not change over certain ranges of $\alpha$ and $\beta$ values. According to the experimental data, a pair of values of $\alpha$, that is, $\left(\alpha_{m 1}, \alpha_{n 1}\right),\left(\alpha_{m 2}, \alpha_{n 2}\right), \ldots \ldots$, $\left(\alpha_{m i}, \alpha_{n i}\right)$ will be determined, when $T=T_{m}$ and $T=T_{n}$, under different heating rates $\beta$. The values of conversion degrees at the same temperature on four TG curves at different heating rates for the title complex are shown in Table 3.By substituting the values of $\alpha$ and $\beta$ in Table 3 , and 41 mechanism functions ${ }^{24}$ into Eqs $(1,2,3)$, then the intercept $a$, the slop $b$ and the linear correlation coefficient $r$ were obtained by Popescu method. The partial results are listed in Table 4 .

Table 3. Conversion degrees at the same temperature and at various heating rates of the complex (Stage I)

\begin{tabular}{|c|c|c|c|c|}
\hline \multirow{2}{*}{$T / \mathrm{K}$} & \multicolumn{4}{|c|}{$\alpha$} \\
\cline { 2 - 5 } & $\beta=3 \mathrm{~K} \cdot \mathrm{min}^{-1}$ & $\beta=5 \mathrm{~K} \cdot \mathrm{min}^{-1}$ & $\beta=10 \mathrm{~K} \cdot \mathrm{min}^{-1}$ & $\beta=15 \mathrm{~K} \cdot \mathrm{min}^{-1}$ \\
\hline 455.04 & 0.2529 & 0.1795 & 0.0949 & 0.0703 \\
\hline 459.35 & 0.3776 & 0.2662 & 0.1376 & 0.1021 \\
\hline 462.53 & 0.4995 & 0.3519 & 0.1821 & 0.1325 \\
\hline 465.02 & 0.6038 & 0.4357 & 0.2257 & 0.1654 \\
\hline 467.23 & 0.7078 & 0.5200 & 0.2714 & 0.1961 \\
\hline
\end{tabular}

\begin{tabular}{|c|c|c|c|c|}
\hline$T / \mathrm{K}$ & $\begin{array}{c}\text { Function } \\
\text { No*}^{*} \text {. }\end{array}$ & $a$ & $b$ & $r$ \\
\hline & 1 & -0.015910 & 0.287309 & 0.997704 \\
\hline & 5 & 0.022364 & 0.173980 & 0.992889 \\
\hline \multirow[t]{5}{*}{$455.02-459.33$} & 15 & 0.157280 & 0.492387 & 0.997632 \\
\hline & 17 & -0.029100 & 0.600640 & 0.997585 \\
\hline & 27 & -0.015910 & 0.280480 & 0.997704 \\
\hline & 1 & -0.021400 & 0.390332 & 0.998325 \\
\hline & 5 & 0.018195 & 0.166440 & 0.994438 \\
\hline \multirow[t]{4}{*}{$459.33-462.51$} & 15 & 0.008144 & 0.551827 & 0.999535 \\
\hline & 17 & -0.050290 & 0.899769 & 0.995401 \\
\hline & 27 & -0.021400 & 0.381215 & 0.998325 \\
\hline & 1 & -0.018860 & 0.405867 & 0.997641 \\
\hline \multirow[t]{3}{*}{$462.51-465.00$} & 15 & 0.010107 & 0.950669 & 0.997219 \\
\hline & 17 & -0.064270 & 1.116903 & 0.996024 \\
\hline & 1 & -0.027350 & 0.492473 & 0.983438 \\
\hline \multirow[t]{2}{*}{$465.00-467.21$} & 15 & -0.004560 & 0.688856 & 0.999798 \\
\hline & 17 & -0.112980 & 1.708084 & 0.991990 \\
\hline
\end{tabular}

Table 4. Partial results by Popescu method at different temperatures of the complex (Stage I)

*The function No. is from Tables 6-10 in ref 24 
As seen from Table 4, the intercept $a$ and the linear correlation coefficient $r$ of the function No.15 is best. Then the probable mechanism function of the first decomposition stage is $g(\alpha)=[-\ln (1-a)]^{3 / 4}, f(\alpha)=3 / 4(1-\alpha)[-\ln (1-a)]^{1 / 4}$.

The calculation of $E$ and $A$

The equation is as follow

$$
\ln \left[\frac{\beta}{T_{n}-T_{m}}\right]=\ln \left[\frac{A}{G(\alpha)_{m n}}\right]-\frac{E}{R T_{\xi}} \quad\left(T_{\xi}=\frac{T_{m}+T_{n}}{2}\right)
$$

The values of temperature at the same degree of conversion for the different heating rates are listed in Table 5. By substituting of the values and the corresponding mechanism function into Eq.(4). Via the Popescu method with $\ln \left[\frac{\beta}{T_{n}-T_{m}}\right]$ versus $1 / T_{\xi}$, the activation $E$ was obtained based on the value

of the slop and the pre-exponential $A$ was also calculated from the value of the intercept. The partial results are presented in Table 6, which are approached to the values of the activation energy by NL-INT method as shown in Fig. 4.

Table 5. Temperatures of the same degree of conversion at different heating rates of the complex (Stage I)

\begin{tabular}{|c|c|c|c|c|}
\hline \multirow[b]{2}{*}{$\alpha$} & \multicolumn{4}{|c|}{$T(\mathrm{~K})$} \\
\hline & $\beta=3 \mathrm{~K} \cdot \mathrm{min}^{-1}$ & $\beta=5 \mathrm{~K} \cdot \mathrm{min}^{-1}$ & $\begin{array}{c}\beta=10 \\
\mathrm{~K} \cdot \min ^{-1}\end{array}$ & $\begin{array}{c}\beta=15 \\
\mathrm{~K} \cdot \min ^{-1}\end{array}$ \\
\hline 0.100 & 445.44 & 448.60 & 455.69 & 459.21 \\
\hline 0.150 & 449.69 & 453.16 & 460.32 & 463.96 \\
\hline 0.200 & 452.53 & 456.21 & 463.61 & 467.38 \\
\hline 0.250 & 454.89 & 458.65 & 466.28 & 469.98 \\
\hline 0.300 & 456.79 & 460.69 & 468.50 & 472.16 \\
\hline 0.350 & 458.49 & 462.46 & 470.36 & 473.83 \\
\hline 0.400 & 459.98 & 464.06 & 472.05 & 475.82 \\
\hline 0.450 & 461.34 & 465.43 & 473.55 & 477.43 \\
\hline 0.500 & 462.58 & 466.78 & 474.99 & 478.85 \\
\hline 0.550 & 463.8 & 467.97 & 476.42 & 480.28 \\
\hline 0.600 & 464.93 & 469.15 & 477.74 & 481.45 \\
\hline 0.650 & 465.98 & 470.26 & 478.95 & 482.75 \\
\hline 0.700 & 467.04 & 471.35 & 480.09 & 484.03 \\
\hline 0.750 & 468.07 & 472.44 & 481.28 & 485.03 \\
\hline 0.800 & 469.19 & 473.59 & 482.58 & 486.35 \\
\hline 0.850 & 470.36 & 474.78 & 483.92 & 487.79 \\
\hline 0.900 & 471.54 & 476.09 & 485.42 & 489.28 \\
\hline
\end{tabular}

Table 6. The values of the kinetic parameters obtained by the Popescu method of the complex

\begin{tabular}{|c|c|c|c|c|c|}
\hline$\alpha_{n}-\alpha_{m}$ & $\begin{array}{c}E / \\
\left(\mathrm{kJ} \cdot \mathrm{mol}^{-1}\right)\end{array}$ & $\begin{array}{c}E^{\mathrm{a}} \\
\left(\mathrm{kJ} \cdot \mathrm{mol}^{-1}\right)\end{array}$ & $\begin{array}{c}A / \times 10^{15} \\
\min \end{array}$ & $\begin{array}{c}A^{\mathrm{a}} / \times 10^{15} \\
\min \end{array}$ & $r$ \\
\hline $0.2-0.1$ & 170.39 & \multirow{11}{*}{164.58} & 4161.61 & \multirow{11}{*}{1522.53} & -0.99797 \\
\hline $0.3-0.1$ & 170.22 & & 3918.02 & & -0.99741 \\
\hline $0.4-0.2$ & 167.23 & & 1627.46 & & -0.99760 \\
\hline $0.8-0.2$ & 162.02 & & 476.33 & & -0.99641 \\
\hline $0.5-0.3$ & 163.10 & & 546.04 & & -0.99794 \\
\hline $0.4-0.3$ & 165.48 & & 997.00 & & -0.99828 \\
\hline $0.5-0.4$ & 160.67 & & 290.29 & & -0.99760 \\
\hline $0.6-0.4$ & 160.52 & & 282.77 & & -0.99509 \\
\hline $0.6-0.5$ & 160.29 & & 266.22 & & -0.99186 \\
\hline $\begin{array}{c}0.75- \\
0.7\end{array}$ & 170.20 & & 3874.48 & & -0.98897 \\
\hline $0.8-0.7$ & 160.29 & & 307.66 & & -0.99336 \\
\hline
\end{tabular}

a Average value of $E$ and $A$.
The thermodynamic parameters of activation can be calculated from the equations: ${ }^{25-26}$

$A \exp (-E / R T)=\operatorname{nexp}\left(-\Delta G^{\neq} / R T\right)$

$$
\Delta H^{\ddagger}=E-R T
$$

$$
\Delta G^{\neq}=\Delta H^{\ddagger}-T \Delta S^{\neq}
$$

Where $\mathrm{n}$ is the Einstein Vibration frequency, $\Delta G^{\ddagger}$ is the Gibbs free enthalpy of activation, $\Delta H^{\ddagger}$ is the enthalpy of activation, $\Delta S^{\ddagger}$ is entropy of activation. The values of $\Delta G^{\ddagger}, \Delta H^{\ddagger}$ and $\Delta S^{\ddagger}$ at the peak temperature obtained based on the Eqs. (5)-(7) are given in Table 7 . The values of $\Delta G^{\ddagger}$ are more than 0 , suggesting that the thermal decomposition reaction of the first step for the title complex is not spontaneous. The values of $\Delta H^{\ddagger}$ are more than 0 , indicating that the reaction belongs to endothermic reaction.

Table 7. The thermodynamic parameters of the complex

\begin{tabular}{|c|c|c|c|c|c|}
\hline \multirow{2}{*}{ Complex } & $\beta / \mathrm{K} \cdot \mathrm{min}^{-1}$ & $\begin{array}{c}\Delta G^{\ddagger} / \\
\mathrm{kJ} \cdot \mathrm{mol}^{-1}\end{array}$ & $\begin{array}{c}\Delta H^{\ddagger} / \\
\mathrm{kJ} \cdot \mathrm{mol}^{-1}\end{array}$ & $\begin{array}{c}\Delta S^{\ddagger} / \\
\mathrm{J} \cdot \mathrm{mol}^{-} \\
1 \cdot \mathrm{K}^{-1}\end{array}$ & $T_{\mathrm{P}} / \mathrm{K}$ \\
\hline \multirow{3}{*}{$\begin{array}{c}{\left[\mathrm{Ho}(\mathrm{BA})_{3}\right.} \\
\text { bipy] }\end{array}$} & 3 & 118.04 & 160.69 & 91.14 & 467.95 \\
\cline { 2 - 6 } & 10 & 117.66 & 160.65 & 91.07 & 472.13 \\
\cline { 2 - 6 } & 15 & 116.61 & 160.56 & 90.87 & 483.68 \\
\cline { 2 - 6 } & $\begin{array}{c}\text { Average } \\
\text { value }\end{array}$ & 117.30 & 160.62 & 91.00 & 476.05 \\
\hline
\end{tabular}

\section{CONCLUSION}

In summary, the complex $\left[\mathrm{Ho}(\mathrm{BA})_{3} \text { (bipy) }\right]_{2}$ was synthesized and characterized. The crystal structure shows that the carboxylic groups coordinated to $\mathrm{Ho}^{3+}$ ion with bidentate bridging and bidentate chelating modes. The coordination number is eight. The mechanism function of the first step for the complex is $g(\alpha)=[-\ln (1-a)]^{3 / 4}, f(\alpha)=3 / 4(1-\alpha)[-\ln (1-a)]^{1 / 4}$. The activation energy $E$, the pre-exponential factor $A$, the enthalpy of activation $\Delta H^{\ddagger}$, the Gibbs free energy of activation $\Delta \mathrm{G}^{\neq}$and the entropy of activation $\Delta \mathrm{S}^{\neq}$were also calculated.

\section{Supplementary Information}

CCDC 711417 is number of $\mathrm{Ho}^{3+}$ complex, which contains the supplementary crystallographic data for this paper. These data can be obtained free of charge from The Cambridge Crystallographic Data Centre via www. ccdc.cam.ac.uk/ data request/cif.

\section{ACKNOWLEDGMENTS}

This project was supported by the National Natural Science Foundation of China $(21073053,20773034)$ and the Natural Science Foundation of Hebei Province ( B2012205022)

\section{REFERENCES}

1. Y.Zhao, J. M.Gao, Chem. Commun. 48, 2997, (2012)

2. Z. Wang, F. Y. Bai, Y. H. Xing, Y. Xie, M. F. Ge, S. Y. Niu, Inorg. Chim. Acta. 363, 669, (2010)

3. X. L. Wang, H. X. Tian, Y. Ma, P. P. Yang, L. C. Li, D. Z. Liao, Inorg. Chem. Commun. 14, 1728,(2011)

4. Y. Y. Yu, J. F. Liu, H. Q. Li, G. L. Zhao, Acta. Phys. Chim.Sin., 26, $1535,(2010)$

5. Y. Zhu, Y. M. Wang, J. Xu, P. Liu, H. A. B. M. D. Weththasinha, Y. L. Wu, X. Q. Lu, J. M. Xie, J Solid State Chem. 219,259,(2014)

6. E. Iravani, N, Nami, F, Nabizadeh, E, Bayani, B, Neumüller, Bull. Korean Chem. Soc. 34, 3420, (2013)

7. L. Song, J.H. Gao, J. Mol. Struct., 1032, 207, (2013)

8. Z.H Lei, K. Zhao, Y.K.Gu, X.Li, J. Rare Earth, 29, 303,(2011)

9. I.G. Fomina , Z.V. Dobrokhotova, A.B. Ilyukhin, G.G. Aleksandrov, V.O. Kazak, A.E. Gehman, N.N. Efimov, A.S. Bogomyakov, Y.S. Zavorotny, V.I. Gerasimova, V.M. Novotortsev, I.L. Eremenko, Polyhedron, 65,152, (2013) 
10. S. Raphael, M. L. P. Reddy, K. V. Vasudevan, A. H. Cowley, Dalton Trans., 4114671,(2012)

11. Y. Zhang, L. P. Jin, S. Z. Lǔ, Chin. J. Inorg. Chem. 13, 280, (1997)

12. S. G.Roh, M. K. Nah, J. B.Oh, N. S. Baek, K. M. Park, H. K. Kim, polyhedron, 24,137, (2005)

13. S.P. Wang, Z.H.Gao, L.J.Xu, R.F.Wang, Acta Crystallogr.,Sect.E:Struct. Rep.Online, 62, m1853, (2006)

14. H. Y. Zhang, K. Z. Wu, J. J. Zhang, S. L. Xu, N. Ren, J. H. Bai, L.Tian, Synth. Met. 158, 157, (2008)

15. L. Tian, N. Ren, J. J. Zhang, S. J. Sun, H. M.Ye, J. H. Bai, R. F. Wang, J. Chem. Eng. Data. 54, 69,(2009)

16. H. M.Ye, N. Ren, H. Li, J. J. Zhang, S. J. Sun, L.Tian, J Therm Anal Calorim. 101, 205,(2010)

17. K. Tang, J. J. Zhang, D. H. Zhang, N. Ren, L. Z. Yan, Y. Li, J. Chem. Thermodynamics 56,38, (2013)
18. J.F.Wang, N. Ren, J. J. Zhang, K. Z.Wu, S.P.Wang, J. Chem. Eng. Data, $55,4982,(2010)$

19. Y.Y.Zhang, N. Ren, L.S.Xu, J. J. Zhang, D.H.Zhang, J Mol Struct, 1081,413, (2015)

20. C. Popescu, Thermochim Acta. 285, 309,(1996)

21. S.Vyazovkin, D. J. Dollimore, Chem. Inf. Comput. Sci.36,42,(1996)

22. B. L. An, M. L. Gong, M. X. Li, J. M. Zhang, J. Mol. Struct. 687, 1,(2004)

23. Z. R. Lu, Y. C. Ding, Y. Xu, B. L. Li, Y. Zhang, Chin. J. Inorg. Chem. 21, $181,(2005)$

24. R. Z. Hu, S. L. Gao, F. Q. Zhao, Q. Z. Shi, T. L. Zhang, J. J. Zhang, Thermal Analysis Kinetics, $2^{\text {th }}$ ed. Science Press, Beijing, 2008, pp 151

25. J. Straszko, M. Olstak-Humienik, J. Mozejko, Thermochim. Acta. 292,145,(1997)

26. M. Olstak-Humienik, J. Mozejko, Thermochim. Acta. 344,73,(2000). 